\title{
Compras públicas compartilhadas: a prática das licitações sustentáveis*
}

Renato Cader da Silva e Teresa Villac Pinheiro Barki

\section{Introdução}

O presente artigo objetiva apresentar as contratações públicas como força motriz no processo de implementação do desenvolvimento sustentável em setores governamentais pouco afeitos à consideração da variável ambiental, quais sejam, os setores de compras. Considerando que a licitação sustentável ainda é tema pouco explorado nas doutrinas jurídica e administrativa e que sua efetividade depende da conjunção de dois campos da ciência, Direito e Administração, que muitas vezes não se comunicam, os autores optaram por apresentar um estudo de caso e, por meio dele, imprimirem os conceitos subjacentes às contratações públicas sustentáveis e à relação destas com a adoção de medidas de gestão pública inovadoras e agregadoras.

Será, então, apresentada a experiência da compra compartilhada de itens de materiais de expediente ambientalmente corretos, levada a efeito pelo Instituto de Pesquisas Jardim Botânico do Rio de Janeiro. O estudo de caso partirá da 
seguinte pergunta: "As compras públicas sustentáveis, efetuadas de forma compartilhada, acarretam ganho de escala e reduzem o valor dos produtos?".

A pertinência da pesquisa refere-se à insipiência dos mercados fornecedores de bens e produtos sustentáveis, acarretando competitividade mais reduzida e preços elevados. Considerando o dever legal de o gestor público implementar o desenvolvimento nacional sustentável com emprego das licitações, há um paradoxo a ser superado, concernente às limitações orçamentárias, à busca por economicidade e à inserção de critérios socioambientais nas contratações.

\section{Sustentabilidade e desenvolvi- mento sustentável: conceitos e aplicações na gestão pública}

Sustentabilidade e desenvolvimento sustentável $^{1}$ são conceitos que transitam nos discursos e preâmbulos de projetos governamentais $^{2}$, bem como nos mais diversos círculos e grupos sociais, muitas vezes com notável e estranho consenso, como se fossem palavras mágicas ou fetiches. Em verdade, é um grande desafio para pesquisadores, gestores públicos, tomadores de decisão, operadores do direito e políticos estabelecerem uma noção aplicável e circunscrita a esses termos.

De acordo com Drummond e Burstyn (2009), sustentabilidade é uma ideia que surgiu em um processo de discussão que inspirou doutrinas, teorias e políticas, desde que a revolução industrial deu margem a preocupações sistemáticas com o desenvolvimento. Nas palavras desses autores: "Sustentável" é uma entre várias palavras ou expressões cunhadas ao longo de muitas décadas para indicar direções preferenciais para o desenvolvimento "integrado", "autônomo", "social", "endógeno", "territorial” etc. (Drummond; BurstYN, 2009, p.11).

Um "sistema sustentável" pode ser considerado como aquele que sobrevive ou persiste (Costanza, 1995; Patten, 1995). Nota-se que há um problema de precisão terminológica para essa definição: qual é o sistema, por quanto tempo ele persiste e quando se pode averiguar se o mesmo persistiu? A aplicação do conceito de sustentabilidade depende do contexto em que está sendo utilizado (Meyer et al., 1993), e é fundamental, portanto, que aqueles que fazem uso do termo especifiquem qual o tipo de conhecimento que está sendo utilizado e de que forma será aplicado.

Conceitos de sustentabilidade e desenvolvimento sustentável têm sido discutidos e criticados por diferentes correntes teóricas e científicas, especialmente no que diz respeito a sua aplicabilidade. O conceito de desenvolvimento sustentável, considerado por muitos como um conceito político, foi colocado em evidência com a iniciativa da ONU (1987) de inserção da expressão em circulação em um encontro internacional que gerou a publicação do relatório Nosso Futuro Comum. O conceito apresentado no relatório revela a preocupação com o bem-estar das populações futuras e a necessidade de serem conciliadas as dimensões econômica, política, social, ambiental e cultural do desenvolvimento.

Desde seu lançamento, o conceito de desenvolvimento sustentável enraizou-se e se espalhou substancialmente no tecido institucional, nas esferas pública e privada, sensibilizou a mídia e moldou o universo das decisões políticas. $\mathrm{Na}$ academia, após um estranhamento inicial, o desenvolvimento 
sustentável alcançou impacto e legitimidade (Drummond; Burstyn, 2009).

O meio ambiente, como objeto de políticas públicas, apresenta um conjunto peculiar de características, que se diferenciam de outras áreas das políticas públicas. Assim, a política ambiental, em regra, atua sobre problemas que envolvem bens comuns, o que implica gerenciar problemas relevantes de ação coletiva. Os benefícios gerados pelo uso de um bem público muitas vezes estão concentrados nas mãos de produtores, enquanto os custos são espalhados amplamente e, muitas vezes, não são internalizados. Essa constatação fundamenta posições, como a do movimento de justiça ambiental, bem como a demanda - inserida no paradigma do desenvolvimento sustentável - por justiça distributiva na presente geração, em especial no que toca aos países em desenvolvimento, e em relação às futuras gerações.

No senso comum e na reprodução discursiva conservadora, as políticas ambientais podem surgir no cenário político com o estigma de as "estragaprazeres". As chamadas ecopolíticas são caracteristicamente alcunhadas de "negativas" em comparação a outras políticas, sempre ressaltando o que não deveria ser feito e enfatizando o lado negativo da implementação de políticas "positivas" (Guimarães, 2006). Nesse contexto, podese considerar que o meio ambiente foi historicamente considerado por políticos, burocratas, empresários, entre outros atores, como um entrave ao desenvolvimento, cuja concepção limitava-se ao crescimento econômico. Assim, é importante destacar que os diversos atores sociais, que participam do processo de formulação de políticas públicas e de tomada de decisão, formam um campo de forças que orientam o rumo dessas políticas, sob a ótica da efetivação dos valores e diretrizes constitucionais.

Ocorre que esse campo de forças está diluído em estruturas institucionais fragmentadas sob o ponto de vista administrativo, o que gera a tendência de que se formulem e executem importantes decisões nas áreas industrial, energética, agrícola, entre outras, sem a devida atenção à questão ambiental. Há, sem dúvida, conflitos de interesses que são evidenciados,
“O meio

ambiente, como

objeto de políticas

puiblicas,

apresenta um

conjunto peculiar

de características,

que se diferenciam

de outras áreas

das políticas

puiblicas." na medida em que na esfera institucional é observada uma preponderância da atuação governamental por meio do comando e controle ${ }^{3}$ sobre as atividades que potencialmente degradam o meio ambiente.

Por outro lado, o uso excessivo e exclusivo dos instrumentos de comando e controle, em conjunto com a multiplicidade e conflito dos diversos atores envolvidos 
na formulação de políticas ambientais, é um fator que contribui para a pouca agilidade, altos custos transacionais e para o comportamento resistente a mudanças. Faz-se necessário ressaltar que as políticas públicas são estruturadas em diversos sistemas constituídos pelo conjunto de atores individuais ou coletivos e de organizações públicas e privadas, que lidam com uma determinada área ou problema de ordem pública. Os atores envolvidos apresentam um conjunto de crenças preestabelecidas sobre como enfrentar adequadamente os diferentes problemas que se lhes apresentam e, mais do que isso, os diferentes projetos políticos e interesses.

Acresça-se que há campos da realidade que não se adaptam ao comando e controle, abarcando situações que ultrapassam os instrumentais por ele oferecidos. $\mathrm{O}$ uso do poder de compra do Estado para fomentar novos mercados sustentáveis é exemplo de opção política que não se perfaz pelo comando e controle.

O Estado tem papel fundamental na redução das tensões entre crescimento econômico e proteção ambiental. Os racionalistas econômicos criticam o uso excessivo do comando e controle e os ambientalistas defendem o crescimento e a aplicação rigorosa da legislação ambiental. À luz desse cenário, o Estado deve atuar como facilitador. Cabe dizer que, além da regulação, há a possibilidade de o Estado atuar em política ambiental pelo incentivo a ações voluntárias, mediante a sensibilização tão defendida pelos românticos verdes e acordos voluntários que são bem aceitos, por exemplo, pelos adeptos do pragmatismo democrático, bem como pelos chamados instrumentos econômicos ${ }^{4}$ de política ambiental.

Há uma extensa lista de instrumentos econômicos já em aplicação no Brasil e em diferentes países. Podem-se citar as "taxas ecológicas”, os subsídios à produção menos poluente e os sistemas de compensação, bem como os impostos e subsídios a equipamentos, processos, insumos e produtos. As contratações públicas sustentáveis podem ser consideradas instrumentos econômicos que incentivam o setor produtivo a investir em meio ambiente e são alternativas cada vez mais presentes e necessárias para mitigar o impasse entre desenvolvimento e meio ambiente, presente na relação entre os diversos atores envolvidos com as políticas ambientais. Elas são relevantes no sentido de incentivar a criação de um padrão de produção sustentável e de uma nova economia, a chamada "economia verde".

Ocorre que tais incentivos dependem de interesses de diversos atores que defendem diferentes objetivos institucionais. Por exemplo, o Ministério da Fazenda visa maximizar a arrecadação, o Ministério do Meio Ambiente visa à conservação e uso sustentável dos recursos naturais, o Ministério do Planejamento visa, entre outras funções, à otimização do gasto público. Há um conflito de metas, o que reflete claramente a complexidade e dificuldades encontradas nas políticas, projetos e iniciativas orientados para o desenvolvimento sustentável.

Nesse contexto, faz-se necessário aperfeiçoar cada vez mais o diálogo entre os diversos atores que tratam de vários temas e áreas de conhecimento nas políticas públicas. Tais atores devem se organizar e construir soluções conjuntas para o desenvolvimento de práticas sustentáveis na gestão pública. A aplicação do conceito de sustentabilidade na gestão pública é um desafio que pode ser concretizado em diversas áreas. As compras compartilhadas sustentáveis são um bom exemplo. 
Contratações públicas sustentáveis: aspectos jurídicos e de gestão pública

O preceito do desenvolvimento sustentável está atrelado a compromissos internacionais assumidos pelo Estado brasileiro e à Constituição Federal (CF). Na esfera do ordenamento nacional, a CF de 1988 estabelece como princípio da ordem econômica "a busca pela defesa do meio ambiente, inclusive, mediante tratamento diferenciado conforme o impacto ambiental de produtos e serviços e de seus processos de elaboração e prestação” (Art. 170). Afirma também que "todos têm direito ao meio ambiente ecologicamente equilibrado, bem de uso comum do povo e essencial à sadia qualidade de vida, impondo-se ao Poder Público e à coletividade o dever de defendêlo e preservá-lo para as presentes e futuras gerações" (Art. 225), e aponta o princípio da eficiência (Art. 37) como um dos norteadores desse preceito (BRASIL, 2010b).

A Lei no 8666/935 (Lei de Licitações e Contratos Administrativos) estabelece em seu Art. $3^{\circ}$ que "a licitação destina-se a garantir a observância do princípio constitucional da isonomia e a selecionar a proposta mais vantajosa para a Administração" (BRAsIL, 2010c). A partir da dicção legal que impôs à administração pública a seleção da proposta mais vantajosa, podese entender, em seu sentido mais amplo, que as propostas aceitas devem ser as mais convenientes para resguardar o interesse público primário e secundário; portanto, o poder público não pode adquirir produtos que provoquem danos ao meio ambiente, por ir de encontro ao interesse público.

A corroborar esse entendimento, a declaração da Conferência Rio 92 indica que "para alcançar o desenvolvimento sustentável, uma qualidade de vida superior a todos os povos, as nações deveriam reduzir e eliminar os padrões de consumo insustentáveis...", bem como a Agenda 21, que dedica um capítulo específico para as mudanças de consumo e ressalta que "para alcançar um desenvolvimento sustentável serão necessárias tanto a eficiência nos processos de produção quanto mudanças nos padrões de consumo" (ONU, 2010b).

As compras públicas sustentáveis aparecem mais explicitamente na Cúpula Mundial sobre Desenvolvimento Sustentável, em Johanesburgo, em dezembro de 2002, impulsionando as autoridades públicas a promoverem políticas de contratação pública que favoreçam o desenvolvimento e a difusão de mercadorias e serviços convenientes ao meio ambiente (BRAsIL, 2011).

No plano nacional, a Lei $\mathrm{n}^{\circ}$ 9.605/98 (Lei de Crimes Ambientais) fortalece entendimento ao estabelecer como sanção para infratores de normas ambientais a impossibilidade de contratar com a administração pública por até três anos ${ }^{6}$ (BRAsIL, 2010d). Também possuem grande relevância nesse tema a Lei no $12.187 / 09$, referente à Política Nacional de Mudanças do Clima, que prevê o estabelecimento de critérios de preferência em licitações para economia de energia, água e outros recursos naturais (Art. 6, inciso XII), bem como a Lei $n^{\circ} 12.305 / 10$, que dispõe sobre a Política Nacional de Resíduos Sólidos (BRASIL, 2010h), ao estimular a adoção de padrões sustentáveis de produção e consumo de bens e serviços (Art. 7, inciso III).

Observa-se que o Brasil já ostenta uma série de instrumentos jurídicos que fundamentam a instituição das licitações sustentáveis. O Ministério do Planejamento publicou em 19 de janeiro de 2010 a Instrução Normativa no 01/2010, que define critérios de sustentabilidade ambiental para 
obras públicas, bens e serviços (BRAsIL, 2010g). Além disso, têm sido realizadas iniciativas de capacitação de gestores e servidores das áreas jurídicas e de compras no sentido de fomentar a realização de contratações sustentáveis no governo federal.

Os gestores públicos, servidores, políticos e tomadores de decisão devem entender que é papel do Estado promover instrumentos econômicos que fomentem a criação de uma nova economia, baseada em produtos e serviços sustentáveis. Os editais sustentáveis podem priorizar produtos em cujos processos produtivos sejam comprovadas ações e medidas adotadas para eficiência energética, economia de água, uso de tecnologias limpas, bem como de matérias-primas provenientes de manejo sustentável, recicladas, reaproveitadas, etc. Os critérios adotados por selos de credibilidade oficiais, como o Selo Socioambiental do Estado de São Paulo, servem como uma boa base para determinar o que constitui um produto sustentável. Há restrições e divergências quanto ao uso e exigência de certificações ambientais em licitações públicas. Assim, é recomendável especificar que um produto observe os critérios estabelecidos por um determinado sistema, sem exigir selo ou certificação privada.

No momento em que um determinado órgão público, de qualquer esfera de governo, elabora um edital com critérios de sustentabilidade, demonstra o início de um novo paradigma nas compras públicas, na medida em que o Estado passa a adquirir produtos sustentáveis, atuando como um consumidor comum. Ao mesmo tempo, sinaliza para o mercado que o seu foco de compras mudou: de produtos tradicionais para produtos menos agressivos ao meio ambiente, considerando a questão social, que envolve direitos humanos e trabalhistas.
A eficiência econômica nas contratações públicas é um desafio, tendo em vista que produtos sustentáveis geralmente são mais caros. O ganho de escala nas compras públicas pode reduzir o preço dos produtos e o Estado tem o papel indutor, no sentido de adotar ações que promovam a formalização de contratos de quantidades maiores. Nesse sentido, uma alternativa inovadora é a realização de compras compartilhadas sustentáveis.

\section{Contextualização das compras públicas sustentáveis no Instituto de Pesquisas Jardim Botânico do Rio de Janeiro}

As compras públicas sustentáveis apresentam um conceito novo, segundo o qual os fornecedores se alinham ao uso racional e inteligente dos recursos naturais, agregando valor aos seus produtos.

Entre 1992 e 2006, observou-se o crescimento significativo da consciência ambiental no Brasil (ISER 1992, 1997, 2001, 2006). Este forte crescimento não estava sendo acompanhado de forma proporcional por ações concretas dos gestores públicos, o que motivou a Diretoria de Gestão do Jardim Botânico do Rio de Janeiro a adotar novas medidas nesse sentido, inserindo nas compras públicas princípios de sustentabilidade.

$\mathrm{Na}$ visão da Diretoria de Gestão, as compras governamentais poderiam influenciar a ampliação de um mercado de produtos e serviços sustentáveis. Estimase que uma parcela significativa do Produto Interno Bruto (PIB), entre 10\% e 15\%, seja oriunda de compras públicas. Logo, se os órgãos públicos comprassem em conjunto por meio de compras compartilhadas sustentáveis, haveria ganho de escala com eficiência econômica, menos impacto 
ambiental e maiores benefícios sociais, o que vai ao encontro da perspectiva do desenvolvimento sustentável.

A experiência de uma compra compartilhada de itens de material de expediente ambientalmente corretos, coordenada e efetivamente implantada pelo Instituto de Pesquisas Jardim Botânico do Rio de Janeiro, com a participação de outros órgãos, é um exemplo concreto da aplicação do conceito de sustentabilidade nas contratações públicas, especificamente nas aquisições.

\section{A experiência da compra} compartilhada sustentável nos órgãos públicos federais do Rio de Janeiro

A experiência da primeira compra compartilhada ocorreu sob a coordenação do Jardim Botânico do Rio de Janeiro (JBRJ) e foram necessários aproximadamente cinco meses para a realização do processo; se observa que anteriormente foram realizadas pesquisas com reuniões preliminares, considerando a abertura do processo em 08/04/2010 e a realização do pregão no dia 20/09/2010.

Inicialmente, foi criada uma equipe multidisciplinar com profissionais especializados em pregões, sustentabilidade e qualidade em processos produtivos. Em seguida, foi realizada pesquisa de mercado e o respectivo cadastramento dos itens nos sistemas estruturantes da administração pública. Após a pesquisa de mercado, foi feita a intenção de registro de preço e realizado o pregão.

\section{Metodologia e procedimentos}

Esta é uma pesquisa exploratória, em que utilizamos o método de estudo de caso, conforme indicado por autores, para responder a questões análogas a este trabalho (YIN, 1994).

Os procedimentos adotados foram documentação e observação direta. Os documentos foram importante instrumental de registro das atividades prévias, concomitantes e posteriores à realização efetiva do pregão. A observação direta, por sua vez, permitiu a obtenção de informações adicionais - nem sempre documentadas - sobre o tema estudado, possibilitando a análise, sob a ótica da administração pública, das medidas e ações que contribuíram para os resultados obtidos com a compra compartilhada de materiais de expediente sustentáveis.

O procedimento preliminar para a realização da compra compartilhada foi a interlocução com o Fórum de Lideranças Executivas de Órgãos Federais no Rio de

\section{Etapas de implementação}

\begin{tabular}{|lcl|}
\hline Etapa & Data & Situação \\
\hline Elaboração da lista & Março/2010 & Concluído \\
\hline Cadastramento & Abril/Maio/2010 & Concluído \\
\hline Pesquisa de mercado & Maio/Junho/2010 & Concluído \\
\hline Intenção de registro de preço (IRP) & Julho/Agosto/2010 & Concluído \\
\hline Realização do pregão & Setembro/2010 & Concluído \\
\hline
\end{tabular}

Fonte: Jardim Botânico do Rio de Janeiro 
Janeiro (GesRio), composto por mais de trinta órgãos, criado e coordenado pelo diretor de Gestão do JBRJ, quem levou a proposta inicial para o grupo. Alguns órgãos participaram - Fundação Oswaldo Cruz (Fiocruz), Instituto Nacional de Propriedade Industrial (Inpi), Ministério da Agricultura, Receita Federal, Ministério da Educação (MEC)/Universidade Federal de Pernanbuco (UFPE), etc. - e outros alegaram que iriam aderir à ata do pregão posteriormente, pois não poderiam comprar naquele momento por estarem com seus estoques cheios.

Nessa situação, apesar dos grandes desafios encontrados (inexperiência dos órgãos com compras sustentáveis e períodos de compras incompatíveis), a equipe do JBRJ empenhou-se em criar um pregão de compra compartilhada, destacando-se como diferencial nesse processo a motivação apresentada pelos membros.
Houve muita dificuldade na elaboração da lista e da pesquisa de mercado, considerando que a mesma foi realizada num mercado incipiente na área de produtos e serviços sustentáveis. O cadastramento dos produtos no sistema do Ministério do Planejamento, Orçamento e Gestão permitiu a codificação dos primeiros produtos sustentáveis de material de expediente. Com o cadastramento, os órgãos e entidades que realizarem novos pregões já vão encontrar esses produtos cadastrados no sistema, eliminando uma etapa em seus processos de compras. A pesquisa no catálogo de produtos sustentáveis ajudou, mas foi necessária uma pesquisa intensa no meio eletrônico e demais meios de comunicação. Foi feita a descrição pormenorizada das especificações dos materiais, considerando material empregado, dimensões, cor, tipo e aplicação. Segue abaixo a lista dos itens sustentáveis que foram submetidos à pesquisa de mercado:

\section{Lista de itens sustentáveis}

\begin{tabular}{|l|l|}
\hline Itens & Produto sustentável \\
\hline 01 & $\begin{array}{l}\text { Almofada para carimbo, material caixa plástico reciclado, material almofada esponja } \\
\text { absorvente revestida de tecido, cor azul, tipo entintada, } 120 \text { de comprimento x } 90 \\
\text { de largura. }\end{array}$ \\
\hline 02 & $\begin{array}{l}\text { Bloco para rascunho, material papel reciclado, sem pauta, } 280 \text { de comprimento } \\
\text { x } 200 \text { de largura, gramatura 56, com } 50 \text { folhas. }\end{array}$ \\
\hline 03 & $\begin{array}{l}\text { Bloco para rascunho, material papel offset, sem pauta, } 210 \text { de comprimento } \\
\text { x } 140 \text { de largura, gramatura 75, com } 50 \text { folhas, quantidade de vias - 1, aplicação } \\
\text { anotações diversas, características adicionais: impressão 1/0 cor, reciclado, com arte, } \\
\text { cor branca. }\end{array}$ \\
\hline 04 & $\begin{array}{l}\text { Bloco para rascunho, material papel reciclado, com pauta, 280 de comprimento } \\
\text { x 200 de largura, gramatura 56, com 50 folhas. }\end{array}$ \\
\hline 05 & $\begin{array}{l}\text { Bloco para rascunho, material papel reciclado, com pauta, } 198 \text { de comprimento } \\
\text { x 150 de largura, gramatura 56, com 50 folhas. }\end{array}$ \\
\hline 06 & $\begin{array}{l}\text { Bloco para recado, material papel reciclado, cor natural, } 38 \text { de largura x } 50 \text { de com- } \\
\text { primento, características adicionais: autoadesivas, com } 100 \text { folhas (tipo postit). }\end{array}$ \\
\hline 07 & $\begin{array}{l}\text { Bloco para recado, material papel reciclado, cor natural, } 76 \text { de largura x 102 de } \\
\text { comprimento, características adicionais: autoadesivo, com } 100 \text { folhas (tipo postit). }\end{array}$ \\
\hline 08 & $\begin{array}{l}\text { Bloco para recado, material papel reciclado, cor natural, } 102 \text { de largura x 152 de } \\
\text { comprimento, características adicionais: autoadesivo, com } 100 \text { folhas (tipo postit). }\end{array}$ \\
\hline
\end{tabular}




\begin{tabular}{|c|c|}
\hline 09 & $\begin{array}{l}\text { Caixa, material polipropileno reciclado, } 280 \text { de comprimento x } 70 \text { de largura x } 250 \\
\text { de altura. }\end{array}$ \\
\hline 10 & $\begin{array}{l}\text { Caixa para embalagem, material papelão reciclado, tipo triplex, } 600 \text { de comprimento } \\
\text { x } 500 \text { de largura x } 400 \text { de altura, cor parda, aplicação acondicionamento de merca- } \\
\text { dorias, espessura } 4,5 \text {, formato retangular, parede dupla, características adicionais: } \\
\text { sem impressão, gramatura } 780 \text {, fechamento lateral cola. }\end{array}$ \\
\hline 11 & $\begin{array}{l}\text { Caixa para embalagem, material papelão reciclado, tipo triplex, } 800 \text { de comprimento } \\
\text { x } 500 \text { de largura x } 400 \text { de altura, cor parda, aplicação acondicionamento de merca- } \\
\text { dorias, espessura } 4,5 \text {, formato retangular, parede dupla, características adicionais: } \\
\text { sem impressão, gramatura } 780 \text {, fechamento lateral cola. }\end{array}$ \\
\hline 12 & $\begin{array}{l}\text { Caixa para embalagem, material papelão reciclado, tipo triplex, } 460 \text { de comprimento x } \\
300 \text { de largura x } 310 \text { de altura, características adicionais: sem impressão, gramatura } 780 \text {. }\end{array}$ \\
\hline 13 & $\begin{array}{l}\text { Classificador, material papelão reciclado, } 350 \text { de comprimento x } 275 \text { de largura, } \\
\text { capacidade 200, características adicionais: ferragem metálica. }\end{array}$ \\
\hline 14 & $\begin{array}{l}\text { Classificador, material papelão reciclado, } 200 \text { de comprimento x } 275 \text { de largura, } \\
\text { capacidade } 200 \text {, características adicionais: ferragem metálica. }\end{array}$ \\
\hline 15 & $\begin{array}{l}\text { Copo descartável, material papel, capacidade } 200 \mathrm{ml} \text {, aplicação água, características } \\
\text { adicionais: não parafinado, gramatura } 146 \mathrm{~g} / \mathrm{m} 2 \text {, cor natural, caixa contendo } 2.500 \\
\text { copos. }\end{array}$ \\
\hline 16 & $\begin{array}{l}\text { Copo descartável, material papel, capacidade } 50 \mathrm{ml} \text {, aplicação café, características adici- } \\
\text { onais: não parafinado, gramatura } 146 \mathrm{~g} / \mathrm{m} 2 \text {, cor natural, caixa contendo } 5.000 \text { copos. }\end{array}$ \\
\hline 17 & $\begin{array}{l}\text { Envelope, material papel reciclado, gramatura } 90,180 \text { de comprimento x } 310 \text { de } \\
\text { largura, cor natural, sem timbre. }\end{array}$ \\
\hline 18 & $\begin{array}{l}\text { Envelope, material papel reciclado, gramatura 90, tipo saco comum, } 230 \text { de com- } \\
\text { primento x } 170 \text { de largura, cor branca, sem timbre. }\end{array}$ \\
\hline 19 & $\begin{array}{l}\text { Envelope, material papel reciclado, gramatura 90, tipo saco comum, } 250 \text { de com- } \\
\text { primento x } 180 \text { de largura, cor parda, colagem lateral, com timbre. }\end{array}$ \\
\hline 20 & $\begin{array}{l}\text { Envelope, material papel reciclado, gramatura 90, tipo saco comum, } 230 \text { de com- } \\
\text { primento x } 160 \text { de largura, cor branca, com timbre. }\end{array}$ \\
\hline 21 & $\begin{array}{l}\text { Envelope, material papel reciclado, gramatura 90, tipo saco comum, } 230 \text { de com- } \\
\text { primento x } 280 \text { de largura, cor branca, sem timbre. }\end{array}$ \\
\hline 22 & $\begin{array}{l}\text { Envelope, material papel reciclado, gramatura 90, tipo saco comum, } 240 \text { de com- } \\
\text { primento x } 340 \text { de largura, cor parda, sem timbre. }\end{array}$ \\
\hline 23 & $\begin{array}{l}\text { Envelope, material papel reciclado, gramatura 90, tipo saco comum, } 340 \text { de com- } \\
\text { primento x } 240 \text { de largura, cor branca, com timbre. }\end{array}$ \\
\hline 24 & $\begin{array}{l}\text { Envelope, material papel reciclado, gramatura 90, tipo saco comum, } 340 \text { de com- } \\
\text { primento x } 240 \text { de largura, cor natural, com timbre. }\end{array}$ \\
\hline 25 & $\begin{array}{l}\text { Envelope, material papel reciclado, gramatura 90, tipo saco comum, } 410 \text { de com- } \\
\text { primento x } 310 \text { de largura, cor natural, sem timbre. }\end{array}$ \\
\hline 26 & $\begin{array}{l}\text { Envelope, material papel reciclado, gramatura 90, tipo saco comum, } 410 \text { de com- } \\
\text { primento x } 310 \text { de largura, cor natural, com timbre. }\end{array}$ \\
\hline 27 & $\begin{array}{l}\text { Envelope, material papel reciclado, gramatura } 90,230 \text { de comprimento x } 115 \text { de } \\
\text { largura, cor branca, sem timbre. }\end{array}$ \\
\hline 28 & $\begin{array}{l}\text { Envelope, material papel reciclado, gramatura 90, tipo saco comum, } 229 \text { de com- } \\
\text { primento x } 162 \text { de largura, cor natural, com timbre. }\end{array}$ \\
\hline
\end{tabular}




\begin{tabular}{|c|c|}
\hline 29 & $\begin{array}{l}\text { Envelope, material papel reciclado, gramatura } 90 \text {, tipo carta, } 110 \text { de comprimento x } \\
230 \text { de largura, cor natural, sem timbre. }\end{array}$ \\
\hline 30 & $\begin{array}{l}\text { Etiqueta adesiva, material papel reciclado, 55,80 de largura x } 99 \text { de comprimento, } \\
\text { formato retangular. }\end{array}$ \\
\hline 31 & $\begin{array}{l}\text { Etiqueta adesiva, material papel reciclado, } 25,40 \text { de largura x } 66,70 \text { de comprimen- } \\
\text { to, formato carta. }\end{array}$ \\
\hline 32 & $\begin{array}{l}\text { Etiqueta adesiva, material papel reciclado, 25,40 de largura x 101,60 de comprimen- } \\
\text { to, formato retangular. }\end{array}$ \\
\hline 33 & $\begin{array}{l}\text { Etiqueta adesiva, material papel reciclado, 101,60 de comprimento x 33,9 de largu- } \\
\text { ra, formato carta. }\end{array}$ \\
\hline 34 & $\begin{array}{l}\text { Formulário contínuo, material papel reciclado, } 1 \text { via, gramatura } 56,80 \text { colunas, } 240 \\
\text { de largura x } 280 \text { de comprimento, características adicionais: microsserrilhado, sem } \\
\text { impressão (caixa com } 2000 \text { folhas). }\end{array}$ \\
\hline 35 & $\begin{array}{l}\text { Formulário contínuo, material papel reciclado, } 1 \text { via, } 132 \text { colunas, } 40 \text { de largura } x \\
280 \text { de comprimento (caixa com } 3000 \text { folhas). }\end{array}$ \\
\hline 36 & $\begin{array}{l}\text { Lápis preto, material corpo de madeira de manejo sustentável, dureza carga 2, ma- } \\
\text { terial carga grafite. }\end{array}$ \\
\hline 37 & $\begin{array}{l}\text { Lápis preto, material corpo de madeira, dureza carga 2, formato corpo sextavado, } \\
\text { material carga grafite preto } \mathrm{n}^{\circ} 2 \text {. }\end{array}$ \\
\hline 38 & $\begin{array}{l}\text { Lapiseira, material plástico reciclado, diâmetro carga } 0,5 \text {, características adicionais: } \\
\text { com prendedor, ponta e acionador de metal/borracha. }\end{array}$ \\
\hline 39 & $\begin{array}{l}\text { Lapiseira, material plástico reciclado, diâmetro carga } 0,7 \text {, características adicionais: } \\
\text { com prendedor, ponta e acionador de metal/borracha. }\end{array}$ \\
\hline 40 & $\begin{array}{l}\text { Livro de protocolo, com } 100 \text { folhas, } 210 \text { de comprimento x } 150 \text { de largura, caracte- } \\
\text { rísticas adicionais: numeradas sequencialmente, material capa papel reciclado, } \\
\text { gramatura das folhas } 56 \text {, material folhas de papel reciclado. }\end{array}$ \\
\hline 41 & $\begin{array}{l}\text { Livro de ata, material papel reciclado, com } 100 \text { folhas, gramatura das folhas } 90,300 \\
\text { de comprimento x } 216 \text { de largura, características adicionais: capa dura, folhas nu- } \\
\text { meradas e pautadas. }\end{array}$ \\
\hline 42 & $\begin{array}{l}\text { Papel A4, material papel reciclado, } 297 \text { de comprimento x } 210 \text { de largura, aplicação } \\
\text { impressora laser e jato de tinta, gramatura } 75 \text {. }\end{array}$ \\
\hline 43 & $\begin{array}{l}\text { Papel A3, material celulose vegetal, } 294 \text { de largura x } 420 \text { de comprimento, gramatura } \\
\text { 120, cor branca, tipo reciclado. }\end{array}$ \\
\hline 44 & $\begin{array}{l}\text { Pasta arquivo, material cartão reciclado, tipo simples, } 310 \text { de largura x } 230 \text { de altura, } \\
\text { cor marrom, gramatura 400, características adicionais: } 210 \text { mm de espessura. }\end{array}$ \\
\hline 45 & Pasta arquivo, material polietileno reciclado, tipo 1, incolor, 240 de largura x 340 de altura. \\
\hline 46 & $\begin{array}{l}\text { Pasta arquivo, material papelão reciclado, tipo suspensa pendular, } 240 \text { de largura x } \\
360 \text { de altura, cor natural, gramatura } 350 \text {, características adicionais: } 3 \text { visor/haste } \\
\text { plástica/etiqueta. }\end{array}$ \\
\hline 47 & $\begin{array}{l}\text { Porta lápis/clipe/lembrete, material polipropileno reciclado, tipo porta lápis, } 85 \text { de } \\
\text { comprimento x } 85 \text { de largura x } 100 \text { de altura. }\end{array}$ \\
\hline 48 & Régua comum, material plástico reciclado, 20 de comprimento, graduação milimétrica. \\
\hline
\end{tabular}

Fonte: Jardim Botânico do Rio de Janeiro 
Após a pesquisa de mercado, o JBRJ realizou o cadastramento da intenção de registro de preço (IRP) no sistema Comprasnet, para que os outros órgãos pudessem fazer suas adesões. Houve, então, a consolidação das demandas dos órgãos participantes e a realização da sessão pública para o dia 20 de setembro de 2010.

\section{Análise dos resultados alcançados}

A compra compartilhada contou com a participação do JBRJ e de mais oito órgãos: Fiocruz (duas unidades), Inpi, Ministério da Fazenda/Receita Federal, Inspetoria da Receita Federal de Macaé, Ministério da Educação/UFPE, Ministério da Agricultura, Ministério do Meio Ambiente e o próprio JBRJ. Com a adesão dos participantes, materializou-se a compra compartilhada sustentável, o que permitiu aumentar o número de unidades do pedido. Conforme a tabela a seguir, observa-se que o ganho de escala permitiu a economia de $\mathrm{R} \$ 723.263,78$, correspondente a 49,89\% do valor estimado (ver quadro abaixo). Foram 48 itens de material de expediente sustentáveis.

Em resposta à questão inicialmente formulada neste estudo: "As compras públicas sustentáveis efetuadas de forma compartilhada acarretam ganho de escala e reduzem o valor dos produtos?". O resultado acima demonstra que foi possível realizar uma compra ambientalmente correta e economicamente eficiente - uma iniciativa reveladora da implantação do consagrado preceito da sustentabilidade nas compras públicas.

\section{Considerações finais}

A realização da compra compartilhada com outros órgãos e com itens de material de expediente sustentáveis atendeu plenamente aos objetivos do projeto, na medida em que houve a participação de oito órgãos na compras de 48 itens sustentáveis de material de expediente. Ressalte-se que o JBRJ sozinho compraria a quantidade de 100 mil itens, e, com os órgãos participantes, a compra chegou a quase 800 mil, com uma economia de aproximadamente $50 \%$ na compra, pelo fato de ter sido compartilhada.

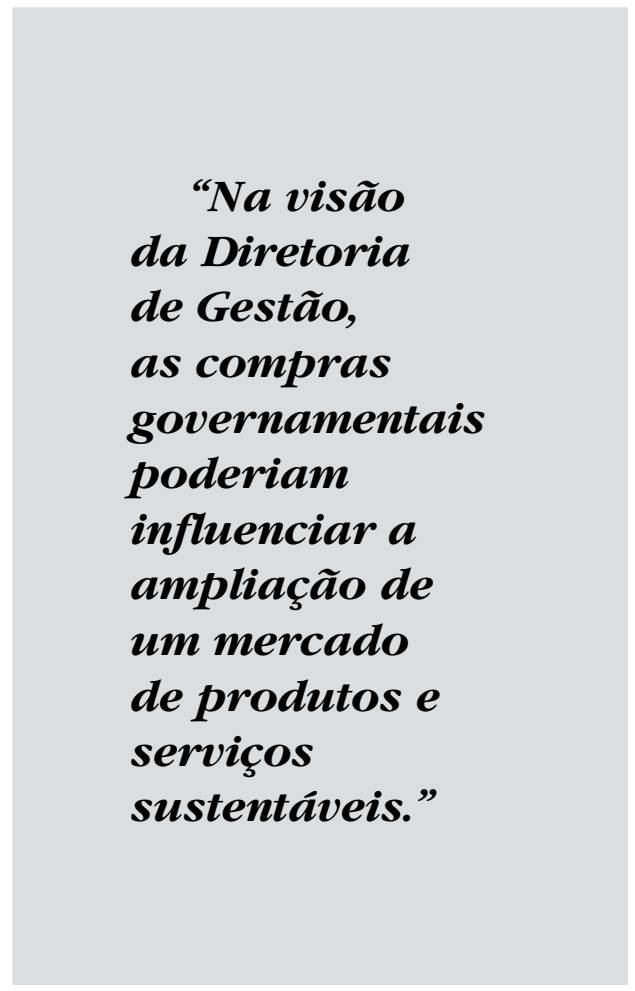

As pessoas atendidas são os consumidores desses produtos, ou seja, os servidores públicos que trabalham nos órgãos. A estimativa é que, no primeiro momento, haverá mais de 10 mil pessoas atendidas, considerando o número de servidores existentes nos órgãos participantes. Após a realização desse pregão, a Diretoria de Gestão autorizou a adesão na 
Economia obtida na compra compartilhada sustentável

\begin{tabular}{|c|c|c|c|c|c|c|}
\hline Item & Materiais & $\begin{array}{c}\text { Valor de } \\
\text { ref. unitário }\end{array}$ & Quantitativo & $\begin{array}{c}\text { Valor de ref. } \\
\text { total }\end{array}$ & $\begin{array}{c}\text { Valor real } \\
\text { unitário }\end{array}$ & Valor real total \\
\hline 1 & $\begin{array}{l}\text { almofada } \\
\text { carimbo }\end{array}$ & $\mathrm{RS} 4,90$ & 300 & R\$ $1.470,00$ & $\mathrm{R} \$ 5,00$ & R\$ $1.500,00$ \\
\hline 2 & bloco & R\$ 1,99 & 3.000 & R\$ $5.970,00$ & $\mathrm{R} \$ 2,00$ & R\$ $6.000,00$ \\
\hline 3 & bloco & $\mathrm{R} \$ 1,49$ & 800 & $\mathrm{R} \$ 1.192,00$ & $\mathrm{R} \$ 5,00$ & R\$ $4.000,00$ \\
\hline 4 & bloco & R\$ 1,49 & 1.100 & R\$ $1.639,00$ & $\mathrm{R} \$ 3,00$ & R\$ $3.300,00$ \\
\hline 5 & bloco & R\$ 1,99 & 850 & R\$ $1.691,50$ & $\mathrm{R} \$ 3,50$ & R\$ $2.975,00$ \\
\hline 6 & bloco & R\$ 6,10 & 39.500 & R\$ $240.950,00$ & $\mathrm{R} \$ 2,00$ & R\$ $79.000,00$ \\
\hline 7 & bloco & R\$ 5,99 & 38.500 & R\$ $230.615,00$ & $\mathrm{R} \$ 2,00$ & R\$ $77.000,00$ \\
\hline 8 & bloco & R\$ 5,90 & 1.400 & $\mathrm{R} \$ 8.260,00$ & R\$ 3,00 & $\mathrm{R} \$ 4.200,00$ \\
\hline 9 & cx polipro & R\$ 3,90 & 3.250 & R\$ $12.675,00$ & $\bullet$ & $\bullet$ \\
\hline 10 & $\mathrm{cx}$ emb. & R\$ 6,90 & 1.750 & R\$ $12.075,00$ & $\bullet$ & $\bullet$ \\
\hline 11 & cx bem. & R\$ 5,99 & 2.000 & R\$ $11.980,00$ & & \\
\hline 12 & cx emb. & R\$ 8,90 & 2.000 & R\$ $17.800,00$ & & \\
\hline 13 & classif. & R\$ 4,49 & 2.600 & R\$ $11.674,00$ & $\mathrm{R} \$ 3,00$ & R\$ $7.800,00$ \\
\hline 14 & classif. & R\$ 4,49 & 1.900 & R\$ $8.531,00$ & R\$ 3,00 & R\$ $5.700,00$ \\
\hline 15 & copo água & $\mathrm{R} \$ 60,63$ & 1.660 & R\$ $100.645,80$ & $\mathrm{R} \$ 60,00$ & R\$ $99.600,00$ \\
\hline 16 & copo café & $\mathrm{R} \$ 38,90$ & 530 & R\$ $20.617,00$ & R\$ 38,89 & RS 20.611,70 \\
\hline 17 & envelope & R\$ 0,12 & 8.000 & R\$ 960,00 & R\$ 0,12 & R\$ 960,00 \\
\hline 18 & envelope & $\mathrm{R} \$ 0,16$ & 7.000 & R\$ $1.120,00$ & $\mathrm{R} \$ 0,10$ & RS 700,00 \\
\hline 19 & envelope & $\mathrm{R} \$ 0,27$ & 7.000 & R\$ $1.890,00$ & $\mathrm{R} \$ 0,08$ & R\$ 560,00 \\
\hline 20 & envelope & R\$ 0,23 & 7.000 & R\$ $1.610,00$ & R\$ 0,07 & R\$ 490,00 \\
\hline 21 & envelope & R\$ 0,13 & 7.000 & R\$ 910,00 & $\mathrm{R} \$ 0,13$ & R\$ 910,00 \\
\hline 22 & envelope & R\$ 0,35 & 40.000 & R\$ $14.000,00$ & R\$ 0,14 & R\$ $5.600,00$ \\
\hline 23 & envelope & R\$ 0,34 & \begin{tabular}{|l|}
42.000 \\
\end{tabular} & R\$ $14.280,00$ & R\$ 0,18 & R\$ $7.560,00$ \\
\hline 24 & envelope & R\$ 0,38 & 85.000 & $\mathrm{R} \$ 32.300,00$ & $\mathrm{R} \$ 0,13$ & $\mathrm{R} \$ 11.050,00$ \\
\hline 25 & envelope & R\$ 0,60 & 50.500 & R\$ $30.300,00$ & R\$ 0,15 & R\$ $7.575,00$ \\
\hline 26 & envelope & $\mathrm{R} \$ 0,30$ & 116.500 & R\$ $34.950,00$ & $\mathrm{R} \$ 0,20$ & RS $23.300,00$ \\
\hline 27 & envebpe & R\$ 0,60 & 25.000 & R\$ $15.000,00$ & R\$ 0,06 & R\$ $1.500,00$ \\
\hline 28 & envelope & R\$ 0,60 & 116.800 & R\$ $70.080,00$ & R\$ 0,08 & R\$ $9.344,00$ \\
\hline 29 & envelope & $\mathrm{R} \$ 0,60$ & 55.000 & R\$ $33.000,00$ & R\$ 0,06 & R\$ $3.300,00$ \\
\hline 30 & etiqueta & R\$ 36,93 & 205 & R\$ $7.570,65$ & R\$ 17,08 & R\$ $3.501,40$ \\
\hline 31 & etiqueta & $R \$ 28,52$ & 235 & R\$ $6.702,20$ & R\$ 17,08 & R\$ $4.013,80$ \\
\hline 32 & etiqueta & R\$ 28,51 & 470 & R\$ $13.399,70$ & R\$ 17,50 & R\$ $8.225,00$ \\
\hline 33 & etiqueta & R\$ 27,79 & 535 & R\$ $14.867,65$ & $\mathrm{R} \$ 16,50$ & R\$ 8.827,50 \\
\hline 34 & form.cont. & R\$ 39,69 & 122 & R\$ $4.842,18$ & $\bullet$ & $\bullet$ \\
\hline 35 & form.cont. & R\$ 69,90 & 100 & R\$ $6.990,00$ & $\bullet$ & $\bullet$ \\
\hline 36 & lápis & R\$ 0,48 & 4.650 & R\$ $2.232,00$ & R\$ 0,40 & R\$ $1.860,00$ \\
\hline 37 & lápis & R\$ 1,90 & 5.885 & R\$ $11.181,50$ & R\$ 1,50 & R\$ $8.827,50$ \\
\hline 38 & lapiseira & R\$ 6,90 & 2.100 & R\$ $14.490,00$ & R\$ 4,87 & $\mathrm{R} \$ 10.227,00$ \\
\hline 39 & lapiseira & R\$ 6,90 & 2.450 & R\$ $16.905,00$ & R\$ 5,87 & R\$ $14.381,50$ \\
\hline 40 & livro prot. & $\mathrm{R} \$ 6,22$ & 1.200 & $\mathrm{R} \$ 7.464,00$ & R\$ 4,98 & R\$ $5.976,00$ \\
\hline 41 & livro-ata & R\$ 8,86 & 900 & R\$ $7.974,00$ & R\$ 5,98 & R\$ $5.382,00$ \\
\hline 42 & papel A4 & $R \$ 16,21$ & 23.000 & $\mathrm{R} \$ 372.830,00$ & R\$ 10,00 & R\$ $230.000,00$ \\
\hline 43 & papel A3 & R\$ 29,20 & 185 & R\$ $5.402,00$ & R\$ 20,00 & R\$ $3.700,00$ \\
\hline 44 & pasta & $\mathrm{R} \$ 3,90$ & 1.500 & R\$ $5.850,00$ & $\mathrm{R} \$ 3,00$ & R\$ $4.500,00$ \\
\hline 45 & pasta & R\$ 1,00 & 1.300 & R\$ $1.300,00$ & R\$ 4,00 & R\$ $5.200,00$ \\
\hline 46 & pasta & R\$ 1,90 & 3.000 & R\$ $5.700,00$ & R\$ 6,50 & RS $19.500,00$ \\
\hline 47 & porta-lápis & R\$ 7,90 & 600 & R\$ $4.740,00$ & R\$ 12,00 & R\$ $7.200,00$ \\
\hline 48 & régua & R\$ 1,90 & 550 & R\$ $1.045,00$ & $\mathrm{R} \$ 1,00$ & $\mathrm{R} \$ 550,00$ \\
\hline & tais & R\$ 49334 & 716.927 & R\$ $1.449 .671,18$ & $\mathrm{R} \$ 280,15$ & RS $726.407,40$ \\
\hline & & TIMATIVA & R\$ 1.449 .67 & 1,18 & LTADO & R\$ $726.407,40$ \\
\hline & & ECONOMIA & R\$ 723.26 & $\%$ ECC & NOMIA & 49,89157472 \\
\hline
\end{tabular}

Fonte: Jardim Botânico do Rio de Janeiro

- Os valores foram cotados na pesquisa de mercado e não foram oferecidos pela empresa vencedora no momento da sessão pública. 
compra compartilhada de outros órgãos, como a Polícia Federal e a Fundação Casa de Rui Barbosa.

A primeira compra compartilhada é um projeto-piloto que deixa um legado para a administração pública federal e isso pode ser revelado com a certeza da segunda compra compartilhada, gerenciada pela Fiocruz. Nesta, já garantiram a participação por meio da manifestação da intenção de registro de preço (IRP) no sistema Comprasnet órgãos que não haviam participado da primeira, como o Instituto Brasileiro de Geografia e Estatística (IBGE), Instituto Nacional de Metrologia, Qualidade e Tecnologia (Inmetro), Banco Nacional de Desenvolvimento Econômico e Social (BNDES), Empresa de Tecnologia e Informações da Previdência Social (Dataprev), Agência Nacional de Cinema (Ancine) e Museu de Astronomia (Mast), entre outros.

A perspectiva é que o projeto seja reverberado por toda a administração pública e que a cada ano um órgão diferente gerencie a compra compartilhada, acumulando conhecimento e expertise no tema. É desejável, portanto, que as experiências sejam multiplicadas, visando ao envolvimento da administração pública em suas diferentes esferas de atuação. É recomendável que os gestores públicos se organizem em redes (conselhos, comitês) para a realização de compras compartilhadas sustentáveis.

Com essa iniciativa, abriu-se nova tendência de compras de material de expediente na administração pública, mas também constatou-se que a legislação vigente carece de regulamentações orientadas ao aperfeiçoamento dos critérios de sustentabilidade dos bens, serviços e obras públicas (nas formas de padronização, especificação e certificação/rotulagem). É necessário que se tenha um programa de governo de apoio a compras públicas sustentáveis, que seja elaborado em conjunto pelas áreas de planejamento, compras e meio ambiente, tendo o Inmetro como parceiro fundamental na definição de critérios de sustentabilidade em processos produtivos de produtos e serviços que vão ser definidos nas licitações como sustentáveis.

Destaca-se, por fim, que o resultado final obtido demonstra que foi possível realizar uma compra ambientalmente correta e economicamente eficiente. A experiência da compra compartilhada de produtos sustentáveis, realizada entre os órgãos públicos do Rio de Janeiro, é um exemplo concreto da implantação do consagrado conceito de desenvolvimento sustentável nas compras públicas.

(Artigo recebido em junho de 2011. Versão final em maio de 2012). 


\section{Notas}

* Este artigo é inspirado numa iniciativa inovadora na gestão pública federal, premiada em quarto lugar na $16^{a}$ edição do Concurso Inovação promovido pela ENAP. A Diretoria de Gestão do Jardim Botânico do Rio de Janeiro (JBRJ) implementou a compra compartilhada sustentável de 48 itens de material de expediente com 10 órgãos da administração pública federal. Essa foi considerada, pelo Ministério do Planejamento, como a primeira compra compartilhada sustentável do governo federal.

1 Este trabalho considera "sustentabilidade" como um conceito ou categoria síntese da proposta de Desenvolvimento Sustentável tal como endossada pela Organização das Nações Unidas a partir da do Relatório Nosso Futuro Comum: "o desenvolvimento sustentável é aquele que atende às necessidades do presente sem comprometer as possibilidades de as gerações futuras atenderem suas próprias necessidades". O mesmo documento define sustentabilidade como um princípio de uma sociedade que mantém as características necessárias para um sistema social justo, ambientalmente equilibrado e economicamente próspero por um período de tempo longo e indefinido (ONU, 1987).

2 As definições, encontradas na literatura, sobre o termo sustentabilidade são diversas. Ferreira (2006) esclarece, por exemplo, que a sustentabilidade mencionada no discurso ecológico oficial é mediada unicamente pela tecnologia, enquanto Goldman (1995) chama a atenção para as distintas definições de biólogos, ecólogos e economistas.

3 Os instrumentos de comando e controle podem ser definidos como um conjunto de regulamentos e normas impostos pelo governo, com a finalidade de restringir as ações que causam impacto ambiental. Como exemplo, podem ser destacados os regulamentos que determinam padrão de emissão de poluentes, as legislações que dispõem sobre o licenciamento de atividades potencialmente poluidoras, que podem proibir a produção, comercialização e uso de produtos específicos.

4 Os instrumentos econômicos (IE) podem ser considerados como alternativas economicamente eficientes e ambientalmente eficazes para complementar as estritas abordagens de comando e controle. Teoricamente, ao fornecer incentivos ao controle da poluição ou de outros danos ambientais, os IE permitem que o custo social de controle ambiental seja menor. Podem, ainda, fornecer aos cofres do governo local receitas fiscais de que tanto se necessita. Os instrumentos econômicos podem ser classificados em dois tipos: (i) incentivos que atuam na forma de prêmios e (ii) incentivos que atuam na forma de preços. Os primeiros requerem um comprometimento de recursos do Tesouro, enquanto os de segundo tipo geram fundos fiscais. Os incentivos que atuam na forma de prêmios são basicamente o crédito subsidiado, as isenções de imposto e outras facilidades contábeis, para efeito de redução da carga fiscal. Os incentivos econômicos via preços são todos os mecanismos que orientam os agentes econômicos a valorizarem os bens e serviços ambientais de acordo com sua escassez e seu custo de oportunidade social. Para tal, atua-se na formação dos preços privados destes bens ou, no caso de ausência de mercados, criam-se mecanismos que acabem por estabelecer um valor social. Em suma, adota-se o "princípio do poluidor/usuário pagador". O objetivo da atuação direta sobre os preços é a internalização dos custos ambientais nos custos privados que os agentes econômicos incorrem no mercado em atividades de produção e consumo (SERÔA DA MotTA \& Mendes, 1996).

${ }^{5}$ A Lei no 12.349 de 15 de dezembro de 2010 altera a Lei no 8.666 de 21 de junho de 1993 e inclui em seu Art. $3^{\circ}$ o termo Desenvolvimento Nacional Sustentável (BrasiL, 2010i).

${ }^{6}$ Art. 72 , parágrafo 8 , inciso $\mathrm{V}$. 


\section{Referências bibliográficas}

BARKI, Teresa. Licitação e desenvolvimento nacional sustentável. In: Revista Debates em Direito Público. Ano 10, no 10, out. 2011.

Biderman, R.; Betiol, L.; Macedo, L.; Monzoni, M.; Mazon, R. (Org.). Guia de compras públicas sustentáveis. Uso do poder de compra do governo para a promoção de desenvolvimento sustentável. $2^{a}$ Edição. Rio de Janeiro: Editora FGV, 2008. ICLEI.

BrasiL. Lei no 6.938, de 31/08/1981. Dispõe sobre a Política Nacional do Meio Ambiente, seus fins e mecanismos de formulação e aplicação e dá outras providências. Disponível em: www.planalto.gov.br/ccivil_03/leis. Acesso em: 15 de abril de 2010.

. Lei n $\mathrm{n}^{\circ} 7.347$, de 24 de julho de 1985. Disciplina a ação civil pública de responsabilidade por danos causados ao meio-ambiente, ao consumidor, a bens e direitos de valor artístico, estético, histórico, turístico e paisagístico (VETADO) e dá outras providências. Disponível em: http://www.planalto.gov.br/ ccivil_03/ Leis/ L7347orig.htm. Acesso em: 02 de março de 2010a.

Constituição da República Federativa do Brasil de 1988. Disponível em: http://www.planalto.gov.br/ccivil_03/Constituicao/Constituicao.htm. Acesso em: 02 de março de $2010 \mathrm{~b}$.

. Lei no 8.666, de 21 de junho de 1993. Regulamenta o Art. 37, inciso XXI, da Constituição Federal, institui normas para licitações e contratos da Administração Pública e dá outras providências. Disponível em: http:/ /www.planalto.gov.br/ ccivil_03/ Leis/L8666cons.htm. Acesso em: 17 de março de 2010c.

. Lei n ${ }^{\circ} 9.605$, de 12 de fevereiro de 1998. Dispõe sobre as sanções penais e administrativas derivadas de condutas e atividades lesivas ao meio ambiente, e dá outras providências. Disponível em: http://www.planalto.gov.br/ccivil_03/Leis/ L9605.htm. Acesso em: 17 de março de 2010d.

. Resolução CONAMA no 307, de 05 de julho de 2002. Disponível em: www.mma.gov.br/port/conama/res/res02/res30702.html Acesso em: 17 de março de 2010e.

. Lei n ${ }^{\circ}$ 12.187, de 29 de dezembro de 2009. Institui a Política Nacional sobre Mudança do Clima (PNMC) e dá outras providências. Disponível em: http:/ / www.planalto.gov.br/ccivil_03/_Ato2007-2010/2009/Lei/L12187.htm. Acesso em: 17 de março de 2010 f.

. Instrução Normativa n ${ }^{\circ}$ 01, de 19 de janeiro de 2010. Dispõe sobre os critérios de sustentabilidade ambiental na aquisição de bens, contratação de serviços ou obras pela Administração Pública Federal direta, autárquica e fundacional e dá outras providências. Disponível em: http:/ / www.cti.ufu.br/sites/cti.ufu.br/files/IN-SLTI-0119 Jan2010-Sustentabilidade-Ambiental.pdf. Acesso em: 17 de março de 2010g.

. Lei n 12.305 , de 02 de agosto de 2010. Dispõe sobre a Política Nacional de Resíduos Sólidos. Disponível em: www.planalto.gov.br. Acesso em: 30 de agosto 2010h.

. Lei n 12.349 , de 15 de dezembro de 2010. Altera as Leis no 8.666, de 21 de junho de 1993, no 8.958, de 20 de dezembro de 1994, e no 10.973, de 2 de dezembro de 2004; e revoga o $\int 1^{\circ}$ do Art. $2^{\circ}$ da Lei $n^{\circ} 11.273$, de 6 de fevereiro de 2006. Disponível 
em: http://www.planalto.gov.br/ccivil_03/_Ato2007-2010/2010/Lei L12349.htm. Acesso em: 17 de dezembro de 2010i.

. Convenção sobre Diversidade Biológica - CDB. Disponível em: www.cdb.gov.br/ cdb. Acesso em: 17 de março de 2010j.

. Guia de Compras Públicas Sustentáveis para a Administração Federal. Ministério do Planejamento, Orçamento e Gestão, 2011.

Catálogo Sustentável. Disponível em: http://www.catalogosustentavel.com.br/ Acesso em: 16 de março de 2010.

CES - FGV. Centro de Estudos em Sustentabilidade da Fundação Getúlio Vargas de São Paulo. Disponível em: www.ces.fgvsp.br

Coletânea de Legislação Ambiental do Senado Federal. Disponível em: http// www.senado.gov.br/sf/senado/programas/senadoverde/legisla_ambiental/pdf/ indice.pdf.

Comissão Européia (2005) / Compras Ecológicas/ Manual sobre a Contratação Pública Ecológica. Oficina de Publicações Oficiais das Comunidades Européias. Luxemburgo. ISBN 92-894-8988-X.

Constanza, R.; Patten, B. C. Defining and predicting sustainability. Ecological Economics (15), 1993.

Drummond, José Augusto (Org.); Burstrn, Marcel (Org.). Desenvolvimento Sustentável: uma ideia com linhagem e legado. Apresentação. Sustentabilidade, Regulação e Desenvolvimento. Revista Sociedade e Estado, Brasília, v. 24, n. 1, p.11-15, jan./abr., 2009.

Goldman, A. Threats to Sustainability in African Agriculture. Human Ecology, 23 (3): 291-334, 1995.

Guimaraes, Roberto P. Facilitating Dialogue Between Science/Policy and Policy/Science: some General Reflections and Proposals for the Path Ahead. First Indp SCIEnCE-POLICY Dialogue Symposium. Berne, Switzerland, September, 2006. p. 21-22.

Meyer, J. L.; Helfman, G. S. The ecological basis of sustainability. Ecological Application, 3(4), 1993.

Ocde (2002). Recommendation of the Council on Improving the Environmental Performance of Public Procurement, C 3, 23/01/2003.

Resolução da Organização das NaÇões Unidas (ONU) nº 39/248, de 16 de abril de 1985. Estabelece Diretrizes para a Proteção ao Consumidor das Nações Unidas. Disponível em: http://www.buscalegis.ufsc.br/revistas/index.php/buscalegis/article/viewArticle/ 24028. Acesso em: 17 de março de 2010.

Santos, Murillo; Barki, Teresa (Org). Licitações e Contratações Públicas Sustentáveis. Belo Horizonte, 2011.

Serôa da Mottta, R. \& Mendes, F. E. Instrumentos econômicos na gestão ambiental: aspectos teóricos e de implementação. In: A Economia Brasileira em Perspectiva - 1996. Rio de Janeiro: IPEA/DIPES, 1996 (b).

United Nations Department of Economic and Social Affairs: division for sustainable development. Agenda 21. Rio de Janeiro, 1992. Disponível em: <www.un.org/esa/dsd/ agenda21/res_agenda21_04.shtml $>$. Acesso em: 8 de março de2010b. 
World Commission on Environment and Development (WCED). Our common future: report of the world commission on environment and development. Oxford: Oxford University, 1987.

YIN, Robert K. Case Study Research: Design and Methods. Sage Publications. $2^{a}$ Edição. 1994. 


\section{Resumo - Resumen - Abstract}

\section{Compras públicas compartilhadas: a prática das licitações sustentáveis} Renato Cader da Silva e Teresa Villac Pinheiro Barki

O presente artigo aborda o tema compras públicas sustentáveis como instrumento econômico capaz de estimular padrões de consumo que incluam critérios ambientais na aquisição de bens e serviços na administração pública. A aplicação do conceito de sustentabilidade nas compras públicas é um desafio, na medida em que devem-se conciliar as dimensões econômica, ambiental e social nas licitações. A análise de como o tema compras sustentáveis ingressa no âmbito da gestão pública é realizada a partir da experiência de uma compra compartilhada de itens de materiais de expediente ambientalmente corretos, coordenada e efetivamente implantada pelo Instituto de Pesquisas Jardim Botânico do Rio de Janeiro, com a participação de outros órgãos. Após a realização do pregão compartilhado, foi possível identificar um ganho de escala que promoveu uma economia de aproximadamente $50 \%$ do valor da proposta inicial, demonstrando a aplicação do conceito de sustentabilidade nas compras públicas.

Palavras-chave: Licitações sustentáveis, compras públicas, sustentabilidade, gestão pública, bens e serviços sustentáveis

\section{Compras públicas compartidas: la práctica de las licitaciones sostenibles Renato Cader da Silva y Teresa Villac Pinheiro Barki}

En este artículo se discute la compra sostenible como un instrumento económico que puede estimular un patrón de consumo que incluye los criterios ambientales en la contratación de bienes y servicios en la administración pública. La aplicación del concepto de sostenibilidad en las compras públicas se trata de un reto, puesto que se deben conciliar las dimensiones económica, ambiental y social en las licitaciones. El análisis de cómo el tema de las compras sostenibles entra en el ámbito de la gestión pública se lleva a cabo a partir de la experiencia de una compra compartida de artículos de oficina respetuosos con el medio ambiente, coordinada y ejecutada con eficacia por el Instituto de Investigaciones Jardín Botánico de Río de Janeiro, con la participación de otros órganos. Tras la realización de la licitación de tipo pregão, se pudo identificar un ahorro del 50\% aproximadamente en relación con la propuesta inicial, lo que demuestra la aplicación del concepto de sostenibilidad en las compras públicas.

Palabras clave: Prácticas sostenibles de adquisición, contratación, sostenibilidad, gobernanza, bienes y servicios sostenibles

\section{Shared public purchases: the practice of sustainable procurement Renato Cader da Silva and Teresa Villac Pinheiro Barki}

This paper discusses sustainable procurement as an economic tool which can stimulate a consumption pattern that includes environmental criteria in procurement of goods and services in public administration. Applying the concept of sustainability in public procurement is a challenge, as it must reconcile the economic, environmental and social bids. The analysis of how sustainable shopping theme enters in the context of public management is carried out from the experience of a shared purchase of items of environmentally friendly supplies, office coordinated and effectively implemented by the Institute for Botanical Garden of Rio de Janeiro with the participation of other institutions. After completion of the trading, was possible to identify a 
shared economies of scale that promoted savings of approximately $50 \%$ of the initial proposal, demonstrating the application of the concept of sustainability in public procurement.

Keywords: Sustainable procurement, procurement, sustainability, governance, sustainable goods and services

Renato Cader da Silva

É doutor em Ambiente e Sociedade pela Universidade Estadual de Campinas (Unicamp), mestre em Administração Pública e de Empresas pela Fundação Getúlio Vargas/RJ (FGV-RJ) e graduado em Administração de Empresas pela Universidade do Estado do Rio de Janeiro (UERJ). Especialista em Políticas Públicas e Gestão Governamental, foi diretor de Gestão do Instituto de Pesquisas Jardim Botânico do Rio de Janeiro. Atualmente está cedido para a Agência Nacional do Cinema (Ancine), exercendo o cargo de gerente executivo. Contato: renato.cader@ancine.gov.br

Teresa Villac Pinheiro Barki

É filósofa pela Universidade de São Paulo (USP) e advogada da Advocacia-Geral da União (AGU), da Consultoria Jurídica da União no Estado de São Paulo. Contato: teresa.barki@agu.gov.br 